DOI 10. 18307/2018. 0205

(C) 2018 by Journal of Lake Sciences

\title{
天津中心城区河网氮磷污染与富营养化特征”
}

\author{
郑剑锋 ${ }^{1,2}$, 焦继东 ${ }^{1}$, 孙力平 ${ }^{1,2}$, 张 硕 $^{1,2}$, 王少坡 ${ }^{1,2}$ \\ ( 1 : 天津城建大学环境与市政工程学院,天津 300384) \\ ( 2 : 天津市水质科学与技术重点实验室, 天津 300384 )
}

\begin{abstract}
摘 要: 2013 年底天津中心城区河道全部连通,形成中心城区河网. 为了掌握河网形成后的水质状况, 于 2014 年 3 月一 2015 年 2 月进行了为期 1 年的定点水质监测, 并对其水体氮、磷时空分布及富营养化特征进行分析. 结果表明, 河网水体 氮污染严重, 以铵态氮 $\left(\mathrm{NH}_{4}^{+}-\mathrm{N}\right)$ 为主; 磷污染程度较轻, 主要形态为磷酸盐 $\left(\mathrm{PO}_{4}^{3-}-\mathrm{P}\right)$; 河网水体中氮、磷浓度顺水流方向 均呈上游高、下游低的空间分布特征; 氮、磷各项指标浓度时间变化趋势基本一致, 3 月均最高, 10 月均最低, 冬季处于相 对较低水平; 与河网形成前相比, 海河干流 $\mathrm{NH}_{4}^{+}-\mathrm{N}$ 、总磷 ( $\mathrm{TP}$ ) 和 $\mathrm{PO}_{4}^{3-}-\mathrm{P}$ 浓度年平均值分别下降 $6.5 \% 、 14.7 \%$ 和 $16.4 \%$, 津 河总氮、 $\mathrm{NH}_{4}^{+}-\mathrm{N}$ 、硝态氮、 $\mathrm{TP}$ 和 $\mathrm{PO}_{4}^{3-}-\mathrm{P}$ 浓度年平均值分别降低 $18.6 \% 、 34.5 \% 、 12.9 \% 、 31.6 \%$ 和 $32.5 \%$, 表明河网形成后氮、 磷污染程度较之前有所改善, 其中津河改善较为明显; 河网水体全年处于中度富营养状态, 主要为磷限制性状态; 河网富 营养化防治应遵循以控制营养盐为主的控源、截污、水环境增容和生态补水策略.
\end{abstract}

关键词: 天津中心城区;河网;氮;磷;富营养化

\section{Pollution characteristics of nitrogen, phosphate and eutrophication of river network water in central urban area of Tianjin}

\author{
ZHENG Jianfeng $^{1,2}$, JIAO Jidong ${ }^{1}$, SUN Liping ${ }^{1,2}$, ZHANG Shuo ${ }^{1,2} \&$ WANG Shaopo ${ }^{1,2}$ \\ (1: School of Environmental and Municipal Engineering, Tianjin Chengjian University, Tianjin 300384, P.R.China) \\ (2: Tianjin Key Laboratory of Aquatic Science and Technology, Tianjin 300384, P.R. China)
}

\begin{abstract}
After the completion of the river network in central urban area of Tianjin, pollution characteristics of nitrogen and phosphate were analyzed and water eutrophication status was assessed based on a field survey from March 2014 to February 2015. The results showed that the river network water was seriously polluted by nitrogen, and slightly contaminated by phosphorus. Ammonia nitrogen $\left(\mathrm{NH}_{4}^{+}-\mathrm{N}\right)$ and orthophosphate $\left(\mathrm{PO}_{4}^{3-}-\mathrm{P}\right)$ were the mainly form of nitrogen and phosphate, respectively. The temporal and spatial variations of nitrogen and phosphate in the river network water were obvious. The concentrations of nitrogen and phosphate in the upper water were both higher than those in the downstream water. During the study period, the concentrations of nitrogen and phosphate reached the highest level in March, then decreased gradually and dropped to the lowest level in October, and kept at low level in winter. Compared with the water status before the river network completion, the annual mean concentration of $\mathrm{NH}_{4}^{+}-\mathrm{N}$, total phosphorus, $\mathrm{PO}_{4}^{3-}-\mathrm{P}$ in Haihe River water decreased by $6.5 \%, 14.7 \%, 16.4 \%$, and the annual mean concentration of total nitrogen, $\mathrm{NH}_{4}^{+}-\mathrm{N}$, nitrate nitrogen, total phosphorus, $\mathrm{PO}_{4}^{3-}-\mathrm{P}$ in Jinhe River water dropped by $18.6 \%, 34.5 \%, 12.9 \%, 31.6 \%, 32.5 \%$, respectively. This showed that nitrogen and phosphate pollution problem of river network water had been obviously improved after the completion of the river network. The results of eutrophication evaluation and characteristic analysis indicated that river network water was in the stage of eutrophication, the algal growth in river network water was limited by phosphorus. The multiple ways including pollutant source control, sewage interception, water environmental capacity increase and ecological water compensation should be used together for eutrophication control.
\end{abstract}

Keywords: Central urban area of Tianjin; river network water; nitrogen; phosphorus; eutrophication

* 天津市自然科学基金项目 (15JCYBJC49100)、天津市水质科学与技术重点实验室开放基金项目 ( TJKLAST-PT2015-01) 和国家自然科学基金项目 (51608349,51678388) 联合资助. 2016-11-29 收稿;2017-11-14 收修改稿. 郑 剑锋(1976 ), 男, 博士, 讲师; E-mail: jianfen1605@163.com. 
天津市地处华北平原东北部, 是海河五大支流的汇合处和人海口, 素有九河下梢之称, 其中心城区河流 众多. 随着海河流域经济快速发展及人类活动日益增强, 来自工业、生活和养殖业等领域的污染排放量显著 增加 ${ }^{[1-3]}$, 使得海河流域水系下游汇聚之地一一天津地区河流污染日趋严重 ${ }^{[4-5]}$, 《天津市水资源公报》显示, 2000 年劣 $\mathrm{V}$ 类河长占评价河长的 $8.1 \%, 2012$ 年剧增至 $74.2 \%$. 加之天津地区河流闸坝多, 河流湖库化 ${ }^{[6]}$, 水 体流动缓慢, 河流来水量逐年减少 ${ }^{[7]}$, 河流自净能力下降, 氮、磷等营养物累积使得其富营养化问题突出 ${ }^{[8-9]}$.

氮、磷营养盐是浮游生物赖以生存的物质基础, 也是导致水体富营养化的主要原因 ${ }^{[10-11]}$, 富营养化水体 常出现藻类异常增殖的水华现象, 严重威胁水生态环境及水质安全 ${ }^{[12-13]}$. 许多学者就天津中心城区河流氮、 磷污染及富营养化问题开展了各项调查研究, 刘春光等 ${ }^{[14]}$ 对津河污染及富营养状况进行调查, 2003 年津河 为劣 $\mathrm{V}$ 类水体, 属重度富营养化状况, 且在多个采样点出现蓝藻水华; 熊代群等 ${ }^{[15]}$ 研究结果显示, 2004 年海 河干流氮污染严重, 各监测点总氮和氨氮浓度均超出 $V$ 类水质标准; 根据时建伟等 ${ }^{[16]}$ 调查, 2006 年卫津河 河水中总氮和总磷浓度远超过 $\mathrm{V}$ 类水质标准, 且在多个采样点出现蓝藻水华现象; 李国锋等 ${ }^{[5]}$ 对天津 12 条 主要河流水质状况的评价结果显示, 2009 年枯水期 $58.3 \%$ 的河流为劣 $\mathrm{V}$ 类水质, 部分河流黑臭, 铵态氮污染 最为严重, 其次是 $\mathrm{BOD}_{5} 、 \mathrm{COD}_{\mathrm{Mn}}$ 和总磷, 属于有机型及富营养化污染. 可见, 天津中心城区河流氮、磷污染及 富营养化问题普遍严重.

近年来, 我国一直持续加大海河流域河流污染治理, 开展包括控源、截污、治污、修河等多项治污举 措 ${ }^{[17]} .2011$ 年天津市开始实施为期 3 年的 “清水工程” 河道污染治理, 建成津河与南运河等多处联通工程, 于 2013 年底打通了中心城区河道循环通道,形成中心城区河网. 目前有关海河流域和天津单一河道氮、磷 污染及富营养化的研究较多, 但缺乏河网形成后的氮、磷污染及富营养化的调查与研究. 本研究于 2014 年 3 月至 2015 年 2 月对天津中心城区河网开展了为期 1 年的水质监测, 对河网形成后水体氮、磷时空分布与富 营养化特征进行研究, 以期为其氮、磷污染及富营养化防治提供依据.

\section{1 材料与方法}

\section{1 研究区概况}

天津市中心城区包括和平区、南开区等 6 个行政区, 区域面积 $173 \mathrm{~km}^{2}$, 下辖人口 386 万, 是天津文化教 育、政治经济及商业中心. 区域属暖温带半湿润大陆性季风气候, 夏季炎热多雨, 冬季寒冷干燥, 年平均气温 $10 \sim 12{ }^{\circ} \mathrm{C}$, 年均降水量为 $522 \sim 663 \mathrm{~mm}, 70 \% \sim 73 \%$ 雨水集中在 7-8 月. 天津市中心城区河网 ( 以下简称河 网) 以海河干流为主,南运河、北运河和子牙河于金刚桥附近汇人海河干流; 河网还包括津河、卫津河等 15 条二级河道,多为景观河道, 兼具排涝功能.

\section{2 数据采集}

本研究在河网水域共设置 7 个采样点, 其中海河干流 2 个 (海河-J1 和海河-J2), 津河 2 个 (津河-J3 和津 河-J4), 南运河 1 个(南运河-J5), 北运河 1 个(北运河-J6), 子牙河 1 个(子牙河-J7), 具体采样点位置如图 1 所示.

自 2014 年 3 月至 2015 年 2 月进行水样采集,采样频率为每旬 1 次,共采样 36 次,采样时间为 $8: 00-$ $14: 00$, 在河流中部采集浅表层 $(0.3 \sim 0.5 \mathrm{~m})$ 河水, 采集量为 $500 \mathrm{ml}$, 装人洁净的 $500 \mathrm{ml}$ 聚乙烯瓶中, 每个水 样采集 3 次, 立即送往实验室低温保存. 水样测试指标包括总氮 $(\mathrm{TN})$ 、铵态氮 $\left(\mathrm{NH}_{4}^{+}-\mathrm{N}\right)$ 、硝态氮 $\left(\mathrm{NO}_{3}^{-}-\mathrm{N}\right)$ 、 总磷 ( $\mathrm{TP}) 、$ 磷酸盐 $\left(\mathrm{PO}_{4}^{3-}-\mathrm{P}\right)$ 和叶绿素 $\mathrm{a}(\mathrm{Chl} . \mathrm{a})$, 水样预处理及分析测试参照国家相关标准方法 ${ }^{[18]}$, 其中, $\mathrm{TN}$ 浓度采用碱性过硫酸钾消解紫外分光光度法, $\mathrm{TP}$ 浓度采用过硫酸钾消解紫外分光光度法, $\mathrm{NH}_{4}^{+}-\mathrm{N}$ 浓度 采用纳氏试剂比色法, $\mathrm{NO}_{3}^{-}-\mathrm{N}$ 浓度采用紫外分光光度法, $\mathrm{PO}_{4}^{3-}-\mathrm{P}$ 浓度采用钿锑抗分光光度法, Chl. a 浓度采 用乙醇冷冻提取法.

河网形成前 (2013 年 1-12 月) 水质数据来源于文献 [ 19], 水质指标包括 $\mathrm{TN} 、 \mathrm{NH}_{4}^{+}-\mathrm{N} 、 \mathrm{NO}_{3}^{-}-\mathrm{N} 、 \mathrm{TP} 、 \mathrm{PO}_{4}^{3-}-\mathrm{P}$ 和 Chl.a.

\section{3 数据分析}

采用 Excel 和 Origin 软件进行数据统计与图表制作; 利用 SPSS 软件中的 Pearson 相关分析研究浮游植 物生物量指标 Chl.a 与氮、磷水质指标之间的关系. 按照国家《地表水环境质量标准》(GB 3838-2002 ${ }^{[20]}$ 评 


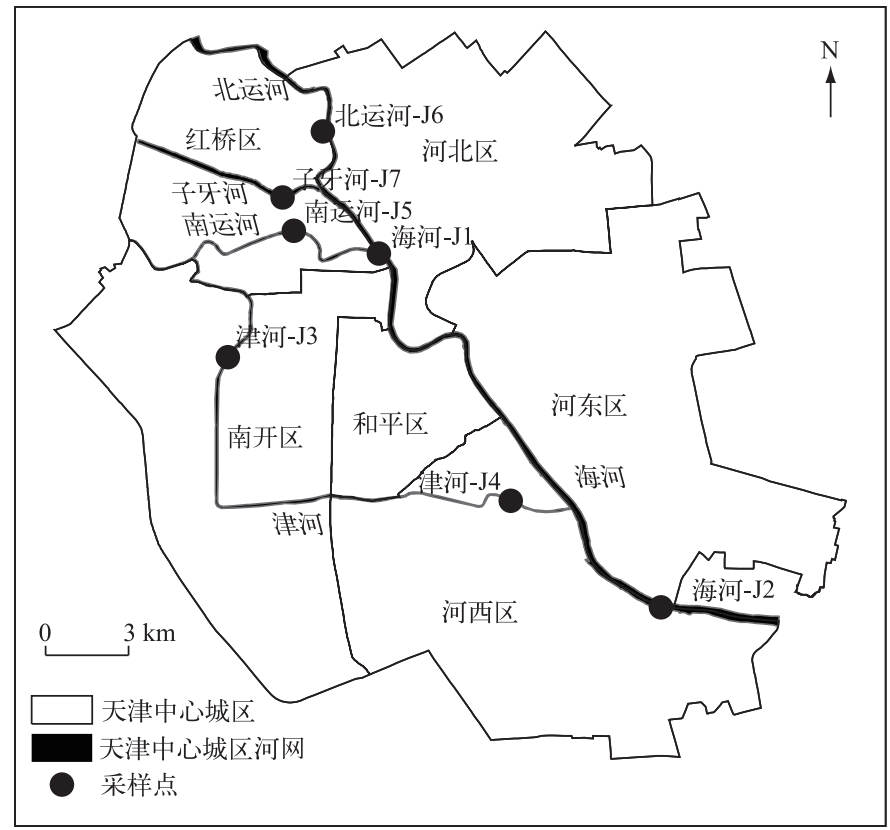

图 1 天津中心城区河网采样点示意

Fig.1 Location of sampling sites in river network water of central urban area of Tianjin

价河网氮、磷污染情况. 采用营养状态评分法 ${ }^{[21]}$, 以 TN、TP 和 Chl.a 为评价指标, 依据式 (1) 计算河网水体 营养状态指数 $(E I)$, 并依据营养状态分级标准 (贫营养 $E I \leqslant 20$, 中营养 $20<E I \leqslant 50$, 轻度富营养 $50<E I \leqslant 60$, 中度富营养 $60<E I \leqslant 80$, 重度富营养 $80<E I \leqslant 100)$ 评价水体营养状态. $E I$ 计算公式为:

$$
E I=\sum_{n=1}^{N} E_{n} / N
$$

式中, $E_{n}$ 为评价项目赋分值; $N$ 为评价项目个数.

\section{2 结果与分析}

\section{1 河网水体氮、磷污染现状分析}

河网水体水质数据统计结果 (表 1) 显示, $\mathrm{TN}$ 和 $\mathrm{NH}_{4}^{+}-\mathrm{N}$ 浓度平均值超过 $\mathrm{V}$ 类水质标准限值 $(\mathrm{TN} \geqslant 2 \mathrm{mg} / \mathrm{L}$, $\left.\mathrm{NH}_{4}^{+}-\mathrm{N} \geqslant 2 \mathrm{mg} / \mathrm{L}\right), \mathrm{NH}_{4}^{+}-\mathrm{N}$ 占 $\mathrm{TN}$ 的 $45.6 \%, \mathrm{NO}_{3}^{-}-\mathrm{N}$ 占 $\mathrm{TN}$ 的 $33.3 \%$; $\mathrm{TP}$ 浓度平均值达到 III 类水质标准 $(0.2$ $\mathrm{mg} / \mathrm{L} \leqslant \mathrm{TP} \leqslant 0.3 \mathrm{mg} / \mathrm{L}), \mathrm{PO}_{4}^{3-}-\mathrm{P}$ 占 $\mathrm{TP}$ 的 $57.2 \%$. 可见, 河网水体 $\mathrm{TN}$ 和 $\mathrm{NH}_{4}^{+}-\mathrm{N}$ 超标情况严重, 以 $\mathrm{NH}_{4}^{+}-\mathrm{N}$ 污染 为主; $\mathrm{TP}$ 浓度相对较低,其主要形态为 $\mathrm{PO}_{4}^{3-}-\mathrm{P}$.

表 1 河网水体氮、磷浓度统计结果

Tab.1 Statistical results of nitrogen and phosphorus concentrations in river network water

\begin{tabular}{cccccc}
\hline 统计指标 & $\mathrm{TN} /(\mathrm{mg} / \mathrm{L})$ & $\mathrm{NH}_{4}^{+}-\mathrm{N} /(\mathrm{mg} / \mathrm{L})$ & $\mathrm{NO}_{3}^{-}-\mathrm{N} /(\mathrm{mg} / \mathrm{L})$ & $\mathrm{TP} /(\mathrm{mg} / \mathrm{L})$ & $\mathrm{PO}_{4}^{3-}-\mathrm{P} /(\mathrm{mg} / \mathrm{L})$ \\
\hline 范围 & $1.73 \sim 15.72$ & $0.06 \sim 13.14$ & $0.02 \sim 5.33$ & $0.016 \sim 0.741$ & $0.008 \sim 0.628$ \\
均值标准差 & $5.40 \pm 2.93$ & $2.46 \pm 2.29$ & $1.80 \pm 0.86$ & $0.201 \pm 0.146$ & $0.110 \pm 0.108$ \\
\hline
\end{tabular}

河网水质极大程度上受上游来水影响, 上游自然来水少且主要为上游地区工农业的污废水. 上游的北 运河、子牙河和南运河沿河分布着众多大中型城市, 人口密集、工业发达、农田面积大、畜禽养殖规模大, 工 业、农业和畜禽养殖业排放人河的氮污染物量大. 《2014 年海河流域水资源公报》显示, 2014 年海河流域工 
业废水排放量高达 23.69 亿 $\mathrm{t}$, 占废污水排放总量的 $43 \%$,主要排污行业为化工、造纸、食品等行业,主要污染 物为化学耗氧量、氨氮 $\left(\mathrm{NH}_{3}-\mathrm{N}\right)$ 等; 2007 年海河流域农业非点源人河污染物 $\mathrm{TN} 8.6$ 万 $\mathrm{t} 、 \mathrm{NH}_{3}-\mathrm{N} 1.1$ 万 $\mathrm{t}^{[22]}$; 2007 年海河流域畜禽养殖产生 TN 116.53 万 $\mathrm{t} 、 \mathrm{NH}_{3}-\mathrm{N} 45.42$ 万 $\mathrm{t}$, 人河 $\mathrm{TN} 0.83$ 万 $\mathrm{t} 、 \mathrm{NH}_{3}-\mathrm{N} 0.58$ 万 $\mathrm{t}^{[23]}$. 上游 大量氮污染物排放人河导致地处海河下游的河网氮污染严重,尤其是氨氮污染问题突出.

上游众多污水处理厂退水不仅是河网的主要补给水源, 同时又是主要的污染源. 根据《城镇污水处理厂 污染物排放标准》( GB 18918-2002 $)^{[24]}$, 污水厂出水 $\mathrm{TN} 、 \mathrm{NH}_{4}^{+}-\mathrm{N}$ 和 $\mathrm{TP}$ 的一级 $\mathrm{A}$ 标准限值分别为 $15 、 5$ 和 $0.5 \mathrm{mg} / \mathrm{L}$, 分别超出《地表水环境质量标准》 $\mathrm{V}$ 类水质限值的 7.5 2.5 和 1.25 倍, $\mathrm{TN} 、 \mathrm{NH}_{4}^{+}-\mathrm{N}$ 的超标倍数远高 于 TP, 这是河网水体氮污染程度远比磷污染严重的主要原因, 也是污水厂退水受纳水体普遍存在的 现象 ${ }^{[25-27]}$.

\section{2 河网水体氮、磷浓度空间分布特征分析}

从空间分布上看 (图 2), 氮、磷浓度顺水流方向呈上游高、下游低的空间分布特征. 河网上游水体 TN、 $\mathrm{NH}_{4}^{+}-\mathrm{N} 、 \mathrm{NO}_{3}^{-}-\mathrm{N}$ 、 $\mathrm{TP}$ 和 $\mathrm{PO}_{4}^{3-}-\mathrm{P}$ 浓度 (海河-J1、津河-J3、南运河-J5、北运河-J6 和子牙河-J7 采样点平均值) 分别 为 $5.60 、 2.63 、 1.83 、 0.204$ 和 $0.12 \mathrm{mg} / \mathrm{L}$, 下游水体 (海河-J2 和津河 $-\mathrm{J} 4$ 采样点平均值) 分别为 $4.92 、 2.04 、 1.80$ 、 0.183 和 $0.101 \mathrm{mg} / \mathrm{L}$, 较上游分别降低 $12.2 \% 、 22.1 \% 、 1.51 \% 、 10.3 \%$ 和 $15.3 \%$. 目前天津市已运行城镇污水处 理厂 70 余座, 总处理规模为 306.48 万 $\mathrm{m}^{3} / \mathrm{d}$, 城市排水管网系统建设取得了很大进步, 基本实现了城区生活 污水和工业废水的集中处理, 在严格控源截污下, 河网水体自净作用使得氮、磷污染物浓度呈顺水流方向下 降的空间分布特征.

河网上游来水的河流中, $\mathrm{TN}$ 和 $\mathrm{NH}_{4}^{+}-\mathrm{N}$ 浓度为北运河 >南运河>子牙河, $\mathrm{NO}_{3}^{-}-\mathrm{N}$ 浓度差异不明显, $\mathrm{TP}$ 和 $\mathrm{PO}_{4}^{3-}-\mathrm{P}$ 浓度均为北运河>子牙河>南运河. 可见, 北运河氮、磷浓度最高, 其 $\mathrm{TN} 、 \mathrm{NH}_{4}^{+}-\mathrm{N} 、 \mathrm{TP}$ 和 $\mathrm{PO}_{4}^{3-}-\mathrm{P}$ 浓度平 均值分别为河网水体的 1.31 、1.72、1.51 和 1.44 倍, 对河网氮、磷贡献最大. 由此可见, 河网水质受上游北运 河、南运河和子牙河的影响较大, 其中受北运河的影响最大. 由于河网水质极大程度上受上游来水影响, 故 仅依靠天津中心城区域内控源、截污等措施不足以解决河网氮磷污染问题,还要与上游地区建立完善的河 流水污染防治协作联动机制, 整体规划、联防联控共同开展河流污染治理, 才是解决河网氮、磷污染的根本 方法.
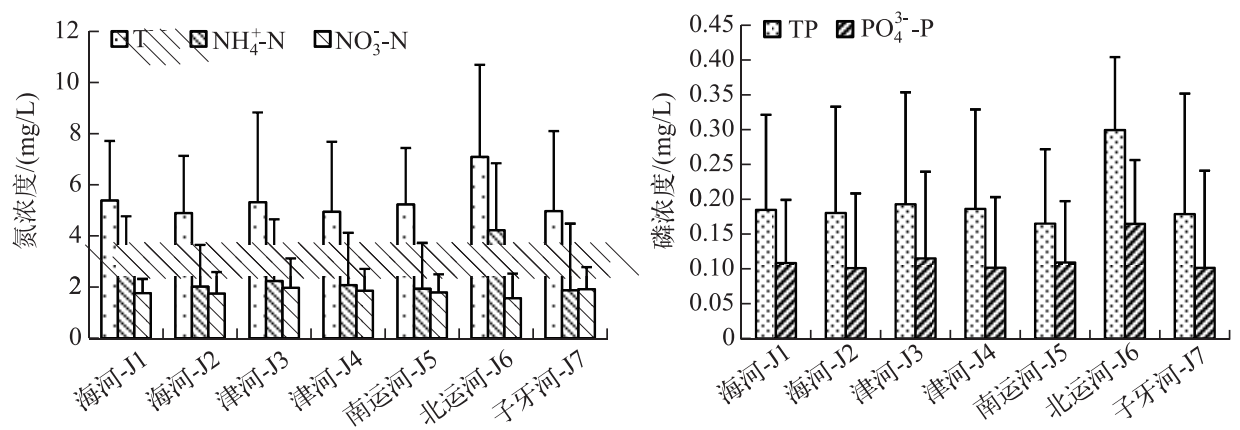

图 2 河网水体中氮、磷浓度的空间分布

Fig.2 Spatial variation of nitrogen and phosphate in river network water

\section{3 河网水体氮、磷浓度时间变化特征分析}

研究期间, 河网水体 $\mathrm{TN} 、 \mathrm{NH}_{4}^{+}-\mathrm{N} 、 \mathrm{NO}_{3}^{-}-\mathrm{N} 、 \mathrm{TP}$ 和 $\mathrm{PO}_{4}^{3-}-\mathrm{P}$ 浓度随时间变化趋势基本一致, 呈明显的春季高、 秋季低的“W”变化趋势 (图 3).

春季平水期内, 3 月河网水体氮、磷浓度水平高且波动大, 这是由于天津地区冬季气温低且普遍降雪, 冬 季取暖导致空气中污染颗粒物增多,通过降雪与自然沉积滞留在地表,一些研究发现降雪所携带的污染物 质比降雨更多, 积雪中的污染物浓度明显高于同一地区雨水 ${ }^{[28-29]}$, 春季积雪融化及少量降雨径流中携带了 大量氮、磷污染物质进人河流, 高负荷氮、磷人河导致河网水体氮、磷浓度高且波动大. 4-5 月降雨量逐渐增 
加, 河流径流量增加, 河网水体更新周期缩短, 氮、磷浓度较 3 月有所降低.

夏季丰水期内, 7-8 月降雨量占全年降雨量 70\% 左右, 城市雨水径流污染严重, 张娜等 ${ }^{[30]}$ 对天津中心 城区雨水径流水质监测发现,夏季降雨径流中 $\mathrm{COD} 、 \mathrm{BOD}_{5} 、 \mathrm{TN}$ 和 $\mathrm{TP}$ 浓度分别超出 $\mathrm{V}$ 类水质标准的 $10 、 50$ 、 2.5 和 2 倍, 河网在雨季需承担防洪排涝的任务, 暴雨期间大量雨水未经处理直接排人河网, 加之截流式合 流制排水系统溢流污水进人河网, 导致进人河网的氮、磷负荷大大增加, 然而大量雨水进人河网稀释了氮、 磷高强度外源输人,使得 7-8 月河网氮、磷浓度水平略有升高但幅度较小.

秋季平水期内, 9 月起城区人河雨水量逐渐减少, 河网上游地区农业生产活动强度有所降低,外源氮、磷 输人大幅降低 ${ }^{[31]}, 10$ 月氮、磷浓度水平降至最低.

冬季枯水期内, 河网水环境容量较丰水期和平水期大大减小, 同时冬季低温不利于水生生物活动 ${ }^{[32]}$, 水 体稀释净化能力相对下降, 氮、磷浓度略有升高. 因此, $3 、 7$ 和 8 月应严格控制进人河网的融雪和雨水径流 氮、磷污染.
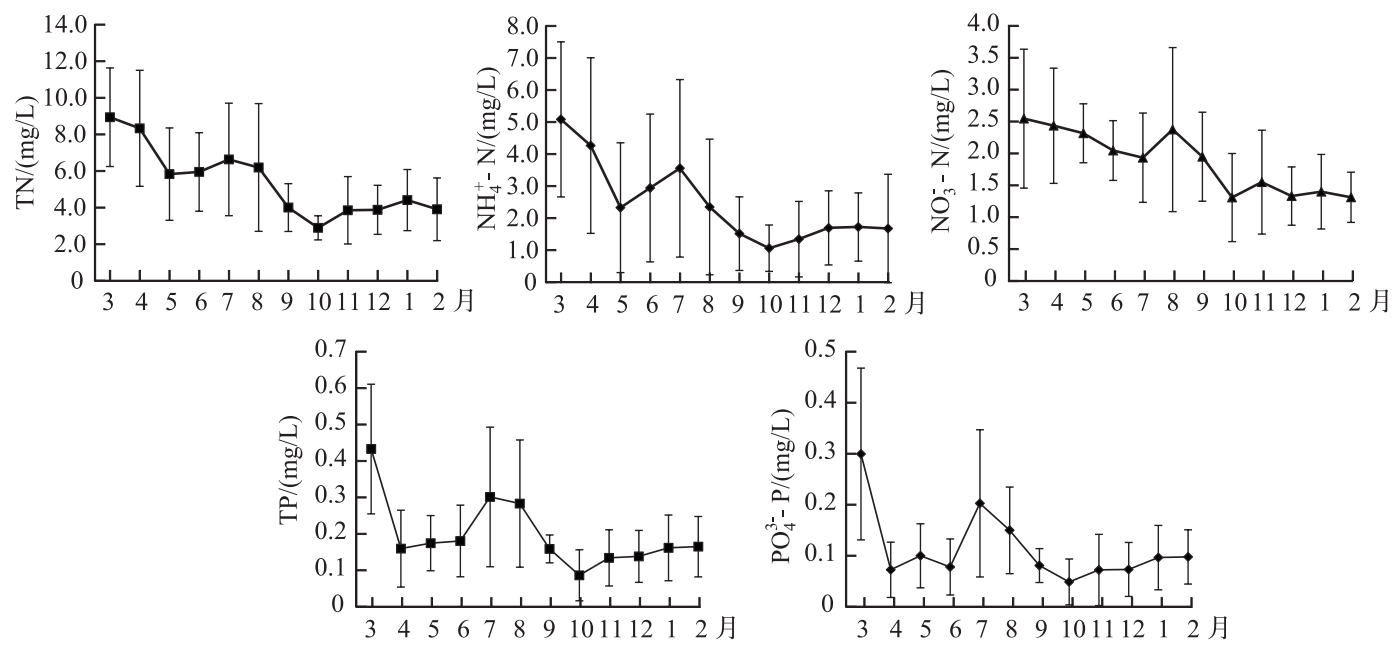

图 3 河网水体中氮、磷浓度的时间分布

Fig.3 Temporal variation of nitrogen and phosphate in river network water

\section{4 河网水体富营养化特征分析}

研究期间,无论从空间分布还是时间变化来看, 河网水体均处于中度富营养化 (图 4). 从空间分布来 看, 北运河 $E I$ 值最高; 从时间变化来看, 3 月和 8 月 $E I$ 值最高. 目前国际上一般认为当水体中的 TN 和 TP 浓 度分别达到 0.2 和 $0.02 \mathrm{mg} / \mathrm{L}$, 就有可能发生水华现象 ${ }^{[33]}$, 当前河网水体 TN 和 TP 浓度远远超出了发生富营 养化的氮、磷条件.

许多研究结果表明, TN/TP 比的变化将改变水体营养物限制性特征, 是调控浮游植物生长的关键因 素 ${ }^{[34-36]}$, 当 TN/TP 比在 $10: 1 \sim 25: 1$ 范围时, 藻类生长与氮、磷浓度存在直线相关关系 ${ }^{[37-38]}$. 根据样本数据统 计分析, TN/TP 比在 5.2 387.9 范围, 有 34.9\%样本在最佳 TN/TP 比范围内, 其中海河-J1 采样点为 $27.8 \%$ 、 海河-J2 采样点为 $30.6 \%$ 、津河-J3 采样点为 $41.7 \%$ 、津河-J4 采样点为 $36.1 \%$ 、南运河-J5 采样点为 $27.8 \%$ 、北 运河-J6 采样点为 $69.4 \%$ 、子牙河-J7 采样点为 $11.1 \%$, 表明河网水体 TN/TP 比有利于藻类生长. 由此可判 断, 河网水体氮、磷营养盐状况完全满足藻类生长繁殖需求, 若在适宜外部环境驱动下, 藻类快速生长繁殖 极易导致水质恶化，事实上每年夏、秋季上述水域均频繁出现水华现象很好地证实了这一推测.

根据 Guildford 等 ${ }^{[39]}$ 提出的水中营养物限制性分类标准, TN/TP $\geqslant 50$ (摩尔比, 换算成质量比约为 22.6) 为磷限制状态, 而 $\mathrm{TN} / \mathrm{TP} \leqslant 20$ (摩尔比, 换算成质量比约为 9.0 ) 为氮限制状态, 本研究 252 个样本中有 $71.4 \%$ 为磷限制状态, 仅有 $1.2 \%$ 属氮限制状态. 此外, 通过 Chl.a 和 TN、TP 的相关分析 (表 2) 也可看出, Chl.a 与 $\mathrm{TN}$ 相关性不显著, 而与 TP 显著相关, 进一步证实了河网属磷限制性水体. 因此, 河网富营养化防治要以 

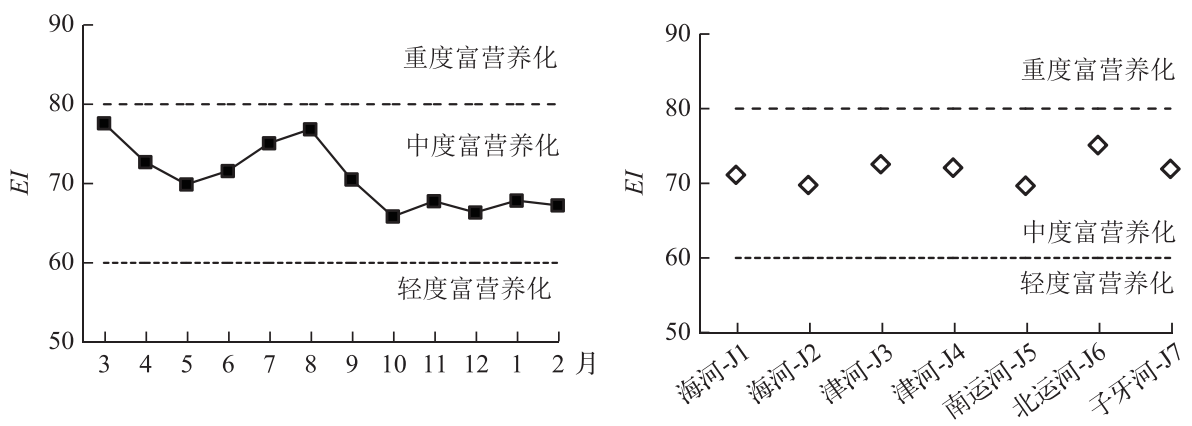

图 4 河网水体营养状态指数值的时空分布

Fig.4 Spatial and temporal variation of $E I$ in river network water

控制磷营养盐为主, 但氮限制状态的存在也表明氮、磷限制状态交替的情况可能存在, 氮也有可能对浮游植 物生长产生影响,所以氮污染治理力度也不能放松, 尤其是要严格控制 $\mathrm{NH}_{4}^{+}-\mathrm{N}$, 以防止水体黑臭.

表 2 相关矩阵

Tab. 2 Correlation matrix

\begin{tabular}{ccllccc}
\hline 相关因子 & $\mathrm{TN}$ & $\mathrm{NH}_{4}^{+}-\mathrm{N}$ & $\mathrm{NO}_{3}^{-}-\mathrm{N}$ & $\mathrm{TP}$ & $\mathrm{PO}_{4}^{3-}-\mathrm{P}$ & $\mathrm{Chl.a}$ \\
\hline $\mathrm{TN}$ & 1 & $0.882^{* *}$ & $0.430^{* *}$ & $0.513^{* *}$ & $0.451^{* * *}$ & 0.057 \\
$\mathrm{NH}_{4}^{+}-\mathrm{N}$ & 1 & $0.138^{*}$ & $0.568^{* *}$ & $0.541^{* *}$ & 0.056 \\
$\mathrm{NO}_{3}^{-}-\mathrm{N}$ & & 1 & -0.032 & -0.112 & 0.082 \\
$\mathrm{TP}$ & & & 1 & $0.908^{* *}$ & $0.385^{* *}$ \\
$\mathrm{PO}_{4}^{3-}-\mathrm{P}$ & & & & 1 & $0.257^{* *}$ \\
$\mathrm{Chl.a}$ & & & & & 1 \\
\hline
\end{tabular}

** 表示在 0.01 水平上显著相关; *表示在 0.05 水平上显著相关.

\section{3 讨论}

\section{1 河网形成前、后水质变化}

河网形成后海河干流 (河网一级河道) $\mathrm{NH}_{4}^{+}-\mathrm{N}$ 、 $\mathrm{TP}$ 和 $\mathrm{PO}_{4}^{3-}-\mathrm{P}$ 浓度年平均值分别下降 $6.5 \%$ 、14.7\% 和 $16.4 \%, \mathrm{TN}$ 和 $\mathrm{NO}_{3}^{-}-\mathrm{N}$ 浓度分别升高了 3.6\% 和 15.6\% (图 5). 从氮污染情况来看, 河网形成前后 $\mathrm{TN}$ 浓度变化 不大, $\mathrm{NH}_{4}^{+}-\mathrm{N}$ 浓度水平有所下降, $\mathrm{NO}_{3}^{-}-\mathrm{N}$ 浓度有所上升. 究其原因, 海河干流水质极大程度上受上游来水影 响, 近年国家持续加大对海河流域河流 COD、氨氮等耗氧污染物治理力度, 至 2009 年海河流域已建成并投 人运行的城镇污水处理厂有 307 座, 总处理能力达 1610 万 $\mathrm{t} / \mathrm{d}$, 分别占全国的 $15.4 \%$ 和 $16.0 \%$, 非常规水资 源利用量为 11.06 亿 $\mathrm{m}^{3}$, 较 2000 年增加了 $204.7 \%, \mathrm{NH}_{4}^{+}-\mathrm{N}$ 是污水处理的主要去除指标, 污水处理率和再生 利用率大幅提高, 有效降低了河流 $\mathrm{NH}_{4}^{+}-\mathrm{N}$ 污染程度, 据张洪等 ${ }^{[40]}$ 调查研究, 近年海河流域河流耗氧污染总 体呈现好转趋势, 耗氧污染指标 $\mathrm{NH}_{4}^{+}-\mathrm{N}$ 呈逐年下降趋势, 故上游来水水质改善是河网形成后 $\mathrm{NH}_{4}^{+}-\mathrm{N}$ 下降的 主要原因; 海河流域河流耗氧污染物治理使得水体亏氧量减小 ${ }^{[40]}, \mathrm{NH}_{4}^{+}-\mathrm{N}$ 在硝化细菌的作用下更容易被氧 化成 $\mathrm{NO}_{3}^{-}-\mathrm{N}$, 所以河网形后 $\mathrm{NH}_{4}^{+}-\mathrm{N}$ 浓度水平下降伴随 $\mathrm{NO}_{3}^{-}-\mathrm{N}$ 浓度的上升. 从磷污染来看, 受上游来水影响 河网形成后 $\mathrm{TP}$ 和 $\mathrm{PO}_{4}^{3-}-\mathrm{P}$ 浓度水平均有所下降, 这主要归因于河网上游地区污水处理以率及污水回用率增 加使得人河磷污染物量减少.

河网形成后, 津河 (河网二级河道) 氮、磷污染明显改善, $\mathrm{TN} 、 \mathrm{NH}_{4}^{+}-\mathrm{N} 、 \mathrm{NO}_{3}^{-}-\mathrm{N} 、 \mathrm{TP}$ 和 $\mathrm{PO}_{4}^{3-}-\mathrm{P}$ 年平均值分别 降低 $18.6 \% 、 34.5 \% 、 12.9 \% 、 31.6 \%$ 和 32.5\% . 2011-2013 年为期 3 年的 “清水工程”治理河道 66 条,新增污 水日处理规模 42.5 万 $\mathrm{t}$, 铺设河流截污管道 $401 \mathrm{~km}$, 解决 1143 家工业废水直排等企业污染问题, 治理 718 家 
规模化养殖场, 封堵污水直排口门 703 座, 污水集中处理率达到 $95 \%$, 排人二级河道的氮、磷污染物大大降 低. 在此期间, 天津中心城区实施了水循环工程, 新建成小王庄河与外环河、津河与南运河等多处联通工程, 新建多处洜站、橡胶坝及节制闸, 打通了中心城区河道循环通道形成中心城区河网, 依托中心城区各项水循 环工程逐步置换中心城区河道水体, 每年向二级河道新补充近 5000 万 $\mathrm{m}^{3}$ 的环境用水. 河网形成后津河氮、 磷污染情况有所好转表明, “清水工程”对天津中心城区二级河道污染治理效果明显.

河网形成后, 海河干流和津河水体 Chl.a 浓度均有所下降, 分别降低 $12.7 \%$ 和 $22.7 \%$. 如前所述, 河网水 体主要为磷限制性水体, Chl. a 浓度与 $\mathrm{TP} 、 \mathrm{PO}_{4}^{3-}-\mathrm{P}$ 浓度呈显著正相关关系, 海河干流和津河 $\mathrm{TP} 、 \mathrm{PO}_{4}^{3-}-\mathrm{P}$ 浓度 水平降低一定程度上抑制了藻类生长繁殖.
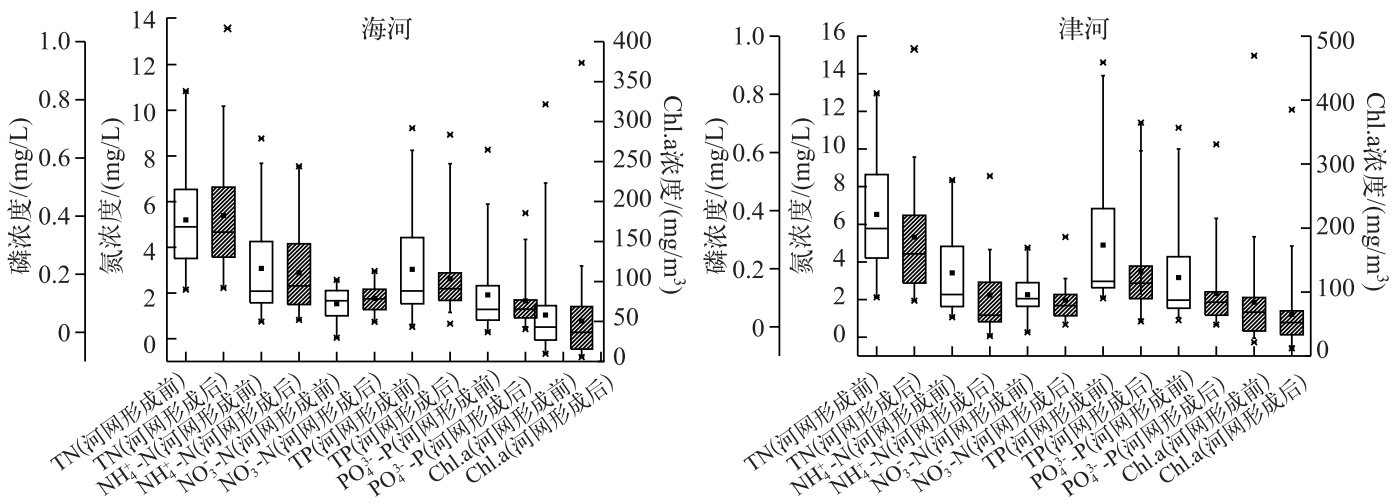

图 5 河网形成前后水质变化

Fig.5 Water quality comparison before and after the completion of the river network

\section{2 河网氮、磷污染与富营养化防治策略}

富营养化的发生是很复杂的, 受多方面因素影响, 如适宜的水温、流速缓慢等, 当然主要原因是水体中 氮、磷等营养物质充足, 导致优势藻类大量繁殖生长, 而使整个水生态系统失衡. 针对河网富营养化问题, 河 网富营养化防治应遵循以控制营养盐浓度为主的“控源截污、水环境增容和生态补水”策略.

控源截污方面,首先应加强对上游来水的监控,与上游地区协同进行河流污染治理; 其次, 据 2013 年 10 月统计, 天津中心城区还有 17 片合流制地区的排水口 34 个, 每年排人河道的雨污水 4000 余万 $\mathrm{m}^{3}$, 故应在 实行雨污完全分流的基础上, 对初期雨水进行分流、收集与集中处理, 尤其是 3 月融雪和首场降雨更应重 视; 河网湖库化, 污染物进人后无法自然排出而是沉积下来造成对底泥的二次污染, 故应定期或不定期进行 底泥疏浚以减少河网内源污染.

水环境增容方面,一方面应加大河道生态工程建设, 通过动、植物的正常生长代谢活动, 消耗水中的氮、 磷等营养物质, 如投放一些鲢鱼等食草性鱼类或种植一些速生、易于采摘、有经济价值的大型水生植物, 以 控制水体的富营养化的发生或发展; 另一方面, 利用中心城区南部的津港运河、洪泥河等河道, 将海河与独 流减河湿地联通起来, 利用中心城区北部的永定新河、金钟河、津唐运河等河道, 将海河与西七里海湿地联 通起来, 形成补水 $\rightarrow$ 流动 $\rightarrow$ 处理 $\rightarrow$ 回补的循环体系, 为河网提供生态水源.

生态补水方面, 目前中心城区及环城四区一、二级河道环境需水量约 3 亿 $\mathrm{m}^{3} / \mathrm{a}$, 多年来一般在重大节日 之前通过引㴒每年向河网补水约 2000 万 $\mathrm{m}^{3}$, 南水北调中线工程通水后, 天津清洁水资源量大大增加, 可增 加水质较好的引滦水向河网的生态补水量, 做到生态补水常态化.

\section{4 结论}

1) 研究期间, 河网 $\mathrm{TN} 、 \mathrm{NH}_{4}^{+}-\mathrm{N}$ 浓度平均值分别为 $5.40 、 2.46 \mathrm{mg} / \mathrm{L}$, 超过 $\mathrm{V}$ 类水质标准; $\mathrm{TP}$ 为 0.201 $\mathrm{mg} / \mathrm{L}$, 达到 III 类水质标准; $\mathrm{NH}_{4}^{+}-\mathrm{N}$ 和 $\mathrm{PO}_{4}^{3-}-\mathrm{P}$ 为氮、磷的主要形态, $\mathrm{NH}_{4}^{+}-\mathrm{N}$ 占 $\mathrm{TN}$ 的 $45.6 \%, \mathrm{PO}_{4}^{3-}-\mathrm{P}$ 占 $\mathrm{TP}$ 的 $57.2 \%$. 河网形成后, 海河干流 $\mathrm{NH}_{4}^{+}-\mathrm{N} 、 \mathrm{TP} 、 \mathrm{PO}_{4}^{3-}-\mathrm{P}$ 浓度年平均值分别下降 $6.5 \% 、 14.7 \%$ 和 $16.4 \%$, 津河 $\mathrm{TN}$ 、 
$\mathrm{NH}_{4}^{+}-\mathrm{N} 、 \mathrm{NO}_{3}^{-}-\mathrm{N} 、 \mathrm{TP}$ 和 $\mathrm{PO}_{4}^{3-}-\mathrm{P}$ 年平均值分别降低 $18.6 \% 、 34.5 \% 、 12.9 \% 、 31.6 \%$ 和 $32.5 \%$, 表明河网形成后氮、 磷污染程度较之前有所改善, 二级河道氮、磷污染改善较为明显.

2) 从空间分布上看,氮、磷浓度顺水流方向呈上游高、下游低的空间分布特征, 河网水质受上游来水影 响极大; 在河网上游来水河流中, 北运河氮、磷浓度水平最高, 对河网水质影响最大, 应为污染治理的重点.

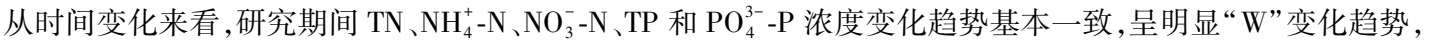
$3 、 7$ 和 8 月处于较高水平,在此期间应严格控制城区融雪和雨水径流氮、磷污染物人河.

3 ) 富营养化评价结果显示, 无论是时间变化还是空间分布, 河网水体均处于中度富营养化状态. 由 TN/TP 特征分析和 Chl.a TN、TP 的相关分析, 可判断河网主要属磷限制性水体, 但氮限制状态的存在也表 明氮、磷限制状态交替的情况可能存在, 所以氮污染治理力度也不能放松, 尤其是要严格控制 $\mathrm{NH}_{4}^{+}-\mathrm{N}$, 以防 止水体黑臭. 河网富营养化防治应遵循以控制营养盐为主的“控源截污、水环境增容和生态补水”策略.

\section{5 参考文献}

[ 1 ] Rong N, Shan BQ, Lin C et al. Evolution of the nitrogen pollution in the Hai River Basin. Acta Scientiae Circumstantiae, 2016, 36(2) : 420-427. [荣楠, 单保庆, 林超等. 海河流域河流氮污染特征及其演变趋势. 环境科学学报, 2016, 36(2) : 420-427.]

[ 2 ] Zhang H, Lei P, Shan BQ et al. Methodology for priority control sequence of river water pollution mitigation and its application in the Haihe River Basin. Acta Scientiae Circumstantiae, 2015, 35(8) : 2306-2313. [张洪, 雷沛, 单保庆等. 河 流污染类型优控顺序确定方法及其在海河流域的应用. 环境科学学报, 2015, 35(8): 2306-2313.]

[ 3 ] Zhu M, Wu JX, Zhang XS. Pollutants loads of livestock and poultry breeding in Hai Basin, China. Journal of Agro-Environment Science, 2010, 29(8): 1558-1565. [ 朱梅, 吴敬学, 张希三. 海河流域畜禽养殖污染负荷研究. 农业环境科 学学报, 2010,29(8): 1558-1565.]

[ 4 ] Yang CC, Wu GH, Chen SR et al. Water quality trend analysis on the Haihe River in Tianjin over the past 25 years. Yellow River, 2013, 35(8): 49-52. [杨灿灿, 吴光红, 陈水蓉等. 近 25 a 来天津市海河干流水质的演变特征. 人民 黄河, 2013, 35(8) : 49-52.]

[ 5 ] Li GF, Liu XB, Liu ZG et al. Water quality assessment of main rivers in Tianjin based on principal component analysis and water quality identification index. Journal of Ecology and Rural Environment, 2011, 27(4): 27-31. [李国锋, 刘宪 斌, 刘占广等. 基于主成分分析和水质标识指数的天津地区主要河流水质评价. 生态与农村环境学报, 2011,27 (4) : 27-31.]

[ 6 ] Shan BQ, Jian YX, Tang WZ et al. Temporal and spatial variation of nitrogen and phosphorus and eutrophication assessment in downstream river network areas of North Canal River watershed. Environmental Science, 2012, 33(2) : 352-358. [单保庆, 菅宇翔, 唐文忠等. 北运河下游典型河网区水体中氮磷分布与富营养化评价. 环境科学, 2012, 33(2): 352-358.]

[ 7 ] Fan CY. Study on sustainable utilization of urban water resources in Tianjin city[Dissertation]. Tianjin: Tianjin University of Technology, 2013. [范翠英. 天津市水资源可持续利用研究 [学位论文]. 天津: 天津理工大学, 2013.]

[ 8 ] Pan LM, Wang XD, Zhao LJ et al. Function recovery and quality improvement of landscape water in Tianjin central district. China Water \& Wastewater, 2012, 28(21): 9-15. [潘留明, 王秀朵, 赵乐军等. 天津中心城区景观水体功能恢 复与水质改善研究. 中国给水排水, 2012, 28(21): 9-15.]

[ 9 ] Zhang H, Lin C, Lei P et al. Evaluation of river eutrophication of the Haihe River Basin. Acta Scientiae Circumstantiae, 2015, 35(8) : 2336-2344. [张洪, 林超, 雷沛等. 海河流域河流富营养化程度总体评估. 环境科学学报, 2015, 35 ( 8 ) : 2336-2344.]

[10] Søndergaard M, Jensen JP, Jeppesen E. Role of sediment and internal loading of phosphorus in shallow. Hydrobiologia, $2003, \mathbf{5 0 6}(1 / 2 / 3): 135-145$.

[11] Pinto U, Maheshwari B, Shrestha S et al. Modelling eutrophication and microbial risks in peri-urban river systems using discriminant function analysis. Water Research, 2012, 46(19) : 6476-6488.

[12] Smith VH, Schindler DW. Eutrophication science: where do we go from here? Trends in Ecology \& Evolution, 2009, 24 (4) : 201-207.

[13] Kong FX, Ma RH, Gao JF et al. The theory and practice of prevention, forecast and warning on cyanobacteria bloom in 
Lake Taihu. J Lake Sci, 2009, 21(3) : 314-328. DOI: 10.18307/2009.0302. [孔繁翔, 马荣华, 高俊峰等. 太湖蓝藻 水华的预防、预测和预警的理论与实践. 湖泊科学, 2009, 21(3) : 314-328.]

[14] Liu CG, Jin XC, Wang W et al. Dynamic analysis of water quality and nutrition status of a landscape river-A case study on Jinhe River in Tianjin. Environmental Pollution \& Control, 2003, 26(4) : 312-316. [刘春光, 金相灿, 王雯等. 城市 景观河流夏季污染状况及营养水平动态分析一一三津市津河为例. 环境污染与防治, 2003, 26(4) : 312-316.]

[15] Xiong DQ, Du XM, Tang WH et al. Nitrogen distribution in the water of the Haihe River mainstream and estuary seawater and its relationship with water dissolved oxygen levels. Research of Environmental Sciences, 2005, 18(3): 1-4. [ 熊代群, 杜晓明, 唐文浩等. 海河天津段与河口海域水体氮素分布特征及其与溶解氧的关系. 环境科学研究, 2005,18 (3) : 1-4.]

[16] Shi JW, Li N. Genesis and control proposal for cyanobacterial bloom in Weijin River. China Water \& Wastewater, 2008, 24(8)：24-26. [时建伟, 李娜. 卫津河蓝藻“水华”形成的原因及治理建议. 中国给水排水, 2008, 24(8): 24-26.]

[17] Shan BQ, Zhang H, Tang WZ et al. Methodology for road map enacting of river pollution mitigation and its application in the Haihe River Basin. Acta Scientiae Circumstantiae, 2015, 35(8): 2297-2305. [单保庆, 张洪, 唐文忠等. 河流污染 治理任务路线图制定方法及其在海河流域的应用. 环境科学学报, 2015, 35(8): 2297-2305.]

[18] Wei FS, Bi T, Qi WQ. Methods for monitoring and analysis of water and wastewater: Fourth Edition. Beijing: Chinese Environmental Science Press, 2002. [魏复盛, 毕粀, 齐文启. 水和废水检测分析方法: 第四版. 北京: 中国环境科学出 版社, 2002.]

[19] Jia ZR, Sun LP, Zhong Y. Changes of chlorophyll-a concentration and its relationship with environmental factors in the Tianjin water body. Journal of Tianjin Chengjian University, 2015, 21(3) : 196-199. [贾振睿, 孙力平, 钟远. 天津市 内水体叶绿素 a 变化及影响环境因子分析. 天津城建大学学报, 2015, 21(3): 196-199.]

[20] State Environmental Protection Administration ed. The surface water environmental quality standard of the People's Republic of China (GB 3838-2002). Beijing: China Environmental Science Press, 2002. [ 国家环境保护总局. 中华人民共和 国地表水环境质量标准( GB 3838-2002). 北京: 中国环境科学出版社, 2002.]

[21] The Ministry of Water Resources of the People's Republic of China ed. Technological regulations for surface water resources quality Assessment (SL395-2007). Beijing: China Water \& Power Press, 2007. [中华人民共和国水利部. 地表水资 源质量评价技术规程 (SL395-2007). 北京: 中国水利水电出版社, 2007.]

[22] Zhu M, Wu JX, Zhang XS. Estimation on non-point source pollution loads of crop farming in Haibasin. Journal of AgroEnvironment Science, 2010, 29(10):1907-1915. [朱梅, 吴敬学, 张希三. 海河流域种植业非点源污染负荷量估算. 农业环境科学学报, 2010, 29(10): 1907-1915.]

[23] Zhu M, Wu JX, Zhang XS. Pollutants loads of livestock and poultry breeding in Haibasin, China. Journal of Agro-Environment Science, 2010, 29(8): 1558-1565. [ 朱梅, 吴敬学, 张希三. 海河流域畜禽养殖污染负荷研究. 农业环境科学 学报, 2010, 29(8):1558-1565.]

[24] State Environmental Protection Administration ed. Discharge standard of pollutants for municipal wastewater treatment plant (GB 18918-2002). Beijing: China Environmental Science Press, 2002. [国家环境保护总局. 城镇污水处理厂污染物 排放标准 (GB 18918-2002). 北京: 中国环境科学出版社, 2002.]

[25] Hu XF, Xu SY, Chen ZL et al. Characteristics of nitrogen and phosphorus pollution in the middle and small creeks, suburban Shanghai. Environmental Science, 2001, 22(6):66-71. [胡雪峰, 许世远, 陈振楼等. 上海市郊中小河流氮磷 污染特征. 环境科学, 2001, 22(6):66-71.]

[26] Zhang XE, Feng CH, Huang BB et al. Pollution characteristics of water system and river system in Haihe basin. Journal of Irrigation and Drainage, 2016, 35(11): 47-51. [张仙娥, 冯成洪, 黄蓓蓓等. 海河流域分水系河系污染特征分析. 灌溉排水学报, 2016, 35(11): 47-51.]

[27] Qing XY, Ren YF, Lü ZQ et al. Characteristics of total nitrogen and total phosphorus pollution and eutrophication assessment of secondary river in urban Chongqing. Environmental Science, 2015, 36(7) : 2446-2452. [庆旭瑶, 任玉芬, 吕志 强等. 重庆市主城区次级河流总氮总磷污染特征分析及富营养化评价. 环境科学, 2015, 36(7): 2446-2452.]

[28] Raynor GS, Hayes JV eds. Differential rain and snow scavenging efficiency implied by ionic concentration differences in winter precipitation. Precipitation scavenging, dry deposition and resuspension: 4th Intern. New York: Elsevier, 1983.

[29] Li HE, Liu ZC, Qin YM et al. Characteristics of snowmelt runoff pollution and comparison with rainfall runoff pollution in Xi'an City. Acta Scientiae Circumstantiae, 2012, 32(11): 2795-2802. [李怀恩, 刘增超, 秦耀民等. 西安市融雪径流 
污染特性及其与降雨径流污染的比较. 环境科学学报, 2012, 32(11) : 2795-2802.]

[30] Zhang N, Zhao LJ, Li TL et al. Characteristics of pollution and monitoring of water quality in Tianjin. Ecology and Environmental Sciences, 2009, 18(6): 2127-2131. [张娜, 赵乐军, 李铁龙等. 天津城区道路雨水径流水质监测及污染 特征分析. 生态环境学报, 2009, 18(6): 2127-2131.]

[31] Yu HY, Hu H, Zeng XG. Spatial-temporal variation of agricultural non-point source pollution in China. Journal of Arid Land Resources and Environment, 2015, 29(9): 1-6. [虞慧怡, 扈豪, 曾贤刚. 我国农业面源污染的时空分异研究. 干旱区资源与环境, 2015, 29(9): 1-6.]

[32] Zhou QC, Xiong Q, Li L et al. The physio-ecological characteristics of algae treated with low temperature and light intensity under different light intensity, nitrogen and phosphorus concentrations. J Lake Sci, 2015, 27 (6) : 1059-1066. DOI: 10. 18307/2015.0610. [ 周起超, 熊倩, 李林等. 经低温、低光处理的藻类在不同光强、氮磷浓度下的生理生态特征. 湖 泊科学, 2015, 27(6): 1059-1066.]

[33] Chen XL, Zhang Y, Zhang L et al. Distribution characteristic of nitrogen and phosphorus in Lake Poyang during high water period. J Lake Sci, 2013, 25(5) : 643-648. DOI: 10.18307/2013.0504. [ 陈晓玲, 张媛, 张琍等. 丰水期鄱阳湖水体 中氮、磷含量分布特征. 湖泊科学, 2013, 25(5): 643-648.]

[34] Tilman D. Resource competition between planktonic algae: An experimental and theoretical approach. Ecology, 1977, 58 (2) : 338-348.

[35] Song YZ, Qin BQ, Gao G. Effect of nutrient on periphyticaglae and phytoplankton. J Lake Sci, 2007, 19(2) : 125-130. DOI: 10.18307/2007.0203. [ 宋玉芝, 秦伯强, 高光. 氮及氮磷比对附着藻类及浮游藻类的影响. 湖泊科学, 2007, 19(2) : 125-130.]

[36] Li Zh, Guo JS, Fang F et al. Potential impact of TN/TP ratio on the cycling of nitrogen in Xiaojiang backwater area, Three Gorges Reservoir. J Lake Sci, 2009, 21 (4) : 509-517. DOI: 10.18307/2009.0409. [李哲, 郭劲松, 方芳等. 三峡水库 小江回水区不同 TN/TP 水平下氮素形态分布和循环特点. 湖泊科学, 2009, 21(4) : 509-517.]

[37] Vollenweider RA. Elemental and biochemical composition of plankton biomass; some comments and explorations. Arch Hydrobiol, 1985, 105: 11-29.

[38] Xie LQ, Xie P, Li SX et al. The low TN: TP ratio, a cause or a result of Microcystis blooms? Water Research, 2003 , 37: 2073-2080.

[39] Guildford SJ, Hecky RE. Total nitrogen, total phosphorus, and nutrient limitation in lakes and oceans: Is there a common relationship? Limnol \& Oceanogr, 2000, 45(6) : 1213-1223.

[40] Zhang H, Lin C, Lei P et al. Trends of pollution by the oxygen-consuming substances and the distribution of oxygen deficiency in the Haihe river basin. Acta Scientiae Circumstantiae, 2015, 35(8) : 2324-2335. [ 张洪, 林超, 雷沛等. 海河 流域河流耗氧污染变化趋势及氧亏分布研究. 环境科学学报, 35(8)：2324-2335.] 